\title{
Foot-and-Mouth Disease in the Middle East Caused by an A/ASIA/G-VII Virus Lineage, 2015-2016
}

\section{Katarzyna Bachanek-Bankowska, Antonello Di Nardo, Jemma Wadsworth, Elisabeth K.M. Henry, Ünal Parlak, Anna Timina, Alexey Mischenko, Ibrahim Ahmad Qasim, Darab Abdollahi, Munawar Sultana, M. Anwar Hossain, Donald P. King, Nick J. Knowles}

Phylogenetic analyses of foot-and-mouth disease type A viruses in the Middle East during 2015-2016 identified viruses belonging to the A/ASIA/G-VII lineage, which originated in the Indian subcontinent. Changes in a critical antigenic site within capsid viral protein 1 suggest possible evolutionary pressure caused by an intensive vaccination program.

$\mathrm{F}$ oot-and-mouth disease (FMD) can decrease productivity in the cloven-hooved livestock industry. As this disease spreads rapidly over large distances, it is regarded as one of the most economically devastating diseases of livestock. FMD is caused by FMD virus (FMDV; family Picornaviridae, genus Aphthovirus), which has $7 \mathrm{im}$ munologically distinct serotypes, O, A, C, Asia 1, SAT 1, SAT 2, and SAT 3. Worldwide, ecologic niches of FMDV circulation have been defined as 7 virus pools. Pools 1-3 are present in Asia, where only serotypes $\mathrm{O}, \mathrm{A}$, and Asia 1 are present.

Serotype A viruses are considered to be the most variable (genetically and antigenically) of Eurasian serotypes. Three topotypes (ASIA, AFRICA, and EURO-SA [Europe-South America]) and multiple diverse lineages and sublineages have been identified (1). The ASIA topotype is widespread and is found in most countries in Asia; there have been sporadic incursions into North Africa. Although the G-VII lineage (also known as genotype 18) $(2,3)$ usually

\footnotetext{
Author affiliations: The Pirbright Institute, Woking, UK

(K. Bachanek-Bankowska, A. Di Nardo, J. Wadsworth, E.K.M. Henry, D.P. King, N.J. Knowles); Foot-and-Mouth Disease Institute, Ankara, Turkey (Ü. Parlak); Federal Centre for Animal Health, Vladimir, Russia (A. Timina, A. Mischenko); Ministry of Environment, Water and Agriculture, Riyadh, Saudi Arabia (I.A. Qasim); Iran Veterinary Organization, Tehran, Iran (D. Abdollahi); University of Dhaka, Dhaka, Bangladesh (M. Sultana, M.A. Hossain)
}

DOI: https://doi.org/10.3201/eid2406.170715 circulates in countries containing virus pool 2 (commonly in Bangladesh and India, rarely in Bhutan and Nepal, but until now not in Sri Lanka), this lineage has also been reported in Saudi Arabia in 1995, Albania and the former Yugoslav Republic of Macedonia in 1996, and Myanmar in 2010.

In India, viruses of the A/ASIA/G-VII lineage were isolated in 1983 (4) and until 2001 were co-circulating with the A/ASIA/G-VI lineage (2). After 2001, only the G-VII lineage has been reported (5). Overall incidence of FMD outbreaks caused by serotype A in India during 2011-2016 was low (3.1\% of the total reported outbreaks). During the same time, $86.8 \%$ of outbreaks were caused by serotype $\mathrm{O}$, and $10.1 \%$ by serotype Asia 1 ( 6 ).

Despite the low number of outbreaks investigated, emergence of a capsid viral protein (VP) 3 deletion variant, $\mathrm{VP}^{59}$, was reported in the A/ASIA/G-VII lineage during 2002 (4). Currently, a group of viruses described as clade $\mathrm{C}$, a subgroup within the $\mathrm{VP} 3^{59}$-deletion variant, is speculated to be the dominant group of the A/ASIA/G-VII lineage prevalent in India (2). We report foot-and-mouth disease in the Middle East during 2015-2016 caused by an A/ASIA/G-VII virus lineage.

\section{The Study}

During outbreak investigations of FMD in Saudi Arabia in 2015, a virus of the A/ASIA/G-VII lineage (VP3 ${ }^{59}$-deletion variant), was identified in cattle (7). The outbreak spread quickly to several strictly monitored dairy farms that had high rates of vaccination, as well as to nomadic herds. Concurrently, related viruses were found in Armenia, Iran, and Turkey in 2015 and continued to circulate in Saudi Arabia, Turkey, and Iran in 2016. Sequences of VP1-coding regions from samples submitted to the Food and Agriculture Organization of the United Nations World Reference Laboratory for FMD (Pirbright, UK) were determined by using described methods (8). VP1 sequences from outbreaks in Armenia, Bangladesh, and Turkey were determined at the Federal Centre for Animal Health (Vladimir, Russia); the University of Dhaka (Dhaka, Bangladesh); and the Foot-and-Mouth Disease Institute (Ankara, Turkey), respectively (Table).

We performed maximum-likelihood analyses to compare VP1 coding sequences with other contemporary sequences of the A/ASIA/G-VII lineage and grouped them within the VP3 ${ }^{59}$-deleted C clade (2) (Figure 1, 
panel A). We estimated time-resolved phylogenetic trees for 101 serotype A FMDV G-VII VP1 sequences by using BEAST version 1.8.4 (9) and incorporated the general time-reversible model with gamma-distributed rate variation among sites and 0.5 prior proportion of invariant sites, the Bayesian Skyline tree before accounting for demographic uncertainty, and a log-normal uncorrelated relaxed clock across branches (10). We ran Markov Chain Monte Carlo analysis for 200 million steps and sampled trees every 20,000 steps after a

Table. Characteristics of 57 strains of foot-and-mouth disease viruses used in analysis of foot-and-mouth disease caused by an A/ASIA/G-VII virus lineage, Middle East, 2015-2016

\begin{tabular}{|c|c|c|c|c|c|}
\hline Virus designation & Country & Location & Species & Date collected & GenBank accession no. \\
\hline A/ARM/1/2015* & Armenia & Armavir, Arazap & Cattle & 2015 Dec 25 & KY982279 \\
\hline A/ARM/2/2015* & Armenia & Armavir, Arazap & Cattle & 2015 Dec 25 & KY982280 \\
\hline A/ARM/3/2015* & Armenia & Armavir, Arazap & Cattle & 2015 Dec 25 & KY982281 \\
\hline $\mathrm{BAN} / \mathrm{CH} / \mathrm{Sa}-304 / 2016$ & Bangladesh & Chittagong & Cattle & 2016 Sep 27 & KY077630 \\
\hline A/IRN/8/2015 & Iran & Qom & Cattle & 2015 Aug 30 & KY982282 \\
\hline A/IRN/12/2015 & Iran & Qom & Cattle & 2015 Sep 9 & KY982283 \\
\hline A/IRN/13/2015 & Iran & Qom & Cattle & 2015 Sep 28 & KY982284 \\
\hline A/IRN/14/2015 & Iran & Qom & Cattle & 2015 Sep 28 & KY982285 \\
\hline A/IRN/17/2015 & Iran & Qom & Cattle & 2015 Oct 9 & KY982286 \\
\hline A/IRN/18/2015 & Iran & Tehran & Cattle & 2015 Oct 10 & KY982287 \\
\hline A/IRN/21/2015 & Iran & Qom & Cattle & 2015 Oct 24 & KY982288 \\
\hline A/IRN/22/2015 & Iran & Tehran & Cattle & 2015 Oct 24 & KY982289 \\
\hline A/IRN/25/2015 & Iran & East Azerbaijan & Cattle & 2015 Oct 28 & KY982290 \\
\hline A/IRN/27/2015 & Iran & Kermanshah & Cattle & 2015 Nov 8 & KY982291 \\
\hline A/IRN/1/2016 & Iran & Qom & Cattle & 2016 Jan 4 & KY982292 \\
\hline A/IRN/8/2016 & Iran & Tehran & Cattle & 2016 Feb 4 & KY982293 \\
\hline A/IRN/11/2016 & Iran & Qazvin & Cattle & 2016 Feb 27 & KY982294 \\
\hline A/IRN/12/2016 & Iran & Ardebil & Cattle & 2016 Feb 29 & KY982295 \\
\hline A/IRN/20/2016 & Iran & Yazd & Cattle & 2016 Feb 4 & KY982296 \\
\hline A/IRN/23/2016 & Iran & Alborz & Cattle & 2016 Apr 7 & KY982297 \\
\hline A/SAU/1/2015 & Saudi Arabia & Farm A, Durma & Cattle & 2015 Sep 2 & KU127247 \\
\hline A/SAU/2/2015 & Saudi Arabia & Farm A, Durma & Cattle & 2015 Sep 2 & KY982298 \\
\hline A/SAU/3/2015 & Saudi Arabia & Farm B, Al Kharj & Cattle & 2015 Oct 9 & KY982299 \\
\hline A/SAU/4/2015 & Saudi Arabia & Farm B, Al Kharj & Cattle & 2015 Oct 19 & KY982300 \\
\hline A/SAU/5/2015 & Saudi Arabia & Farm C, Al Kharj & Cattle & 2015 Oct 16 & KY982301 \\
\hline A/SAU/6/2015 & Saudi Arabia & Farm A, Durma & Cattle & 2015 Oct 21 & KY982302 \\
\hline A/SAU/7/2015 & Saudi Arabia & Farm D, Al Kharj & Cattle & 2015 Oct 23 & KY982303 \\
\hline A/SAU/8/2015 & Saudi Arabia & Farm D, Al Kharj & Cattle & 2015 Dec 30 & KY982304 \\
\hline A/SAU/9/2015 & Saudi Arabia & Al Kharj & Cattle & 2015 Oct 5 & KY982305 \\
\hline A/SAU/14/2015 & Saudi Arabia & Al Kharj & Sheep & 2015 Oct 26 & KY982306 \\
\hline A/SAU/15/2015 & Saudi Arabia & Al Kharj & Sheep & 2015 Oct 26 & KY982307 \\
\hline A/SAU/16/2015 & Saudi Arabia & Al Kharj & Sheep & 2015 Oct 26 & KY982308 \\
\hline A/SAU/17/2015 & Saudi Arabia & Al Kharj & Sheep & 2015 Oct 26 & KY982309 \\
\hline A/SAU/21/2015 & Saudi Arabia & Al Kharj & Cattle & 2015 Dec 22 & KY982310 \\
\hline A/SAU/15/2016 & Saudi Arabia & Farm D, Al Kharj & Cattle & 2016 Mar 27 & KY982311 \\
\hline A/SAU/19/2016 & Saudi Arabia & Farm C, Al Kharj & Cattle & 2016 Oct 14 & KY982312 \\
\hline A/SAU/20/2016 & Saudi Arabia & Farm C, Al Kharj & Cattle & 2016 Oct 14 & KY982313 \\
\hline A/SAU/21/2016 & Saudi Arabia & Mekkah & Cattle & 2016 Oct 19 & KY982314 \\
\hline A/SAU/22/2016 & Saudi Arabia & Mekkah & Cattle & 2016 Oct 19 & KY982315 \\
\hline A/SAU/24/2016 & Saudi Arabia & Mekkah & Cattle & 2016 Oct 19 & KY982316 \\
\hline A/SAU/37/2016 & Saudi Arabia & Al Kharj & Cattle & 2016 Dec 29 & KY982317 \\
\hline A/SAU/40/2016 & Saudi Arabia & Al Kharj & Cattle & 2016 Dec 29 & KY982318 \\
\hline A/SAU/41/2016 & Saudi Arabia & Al Kharj & Cattle & 2016 Dec 29 & KY982319 \\
\hline A/SAU/42/2016 & Saudi Arabia & Al Kharj & Cattle & 2016 Dec 29 & KY982320 \\
\hline A/TUR/175/2015.712* & Turkey & Van & Cattle & 2015 Sep 29 & KY982321 \\
\hline A/TUR/198/2015.808* & Turkey & Van & Cattle & 2015 Oct 15 & KY982322 \\
\hline A/TUR/203/2015.827* & Turkey & Van & Cattle & 2015 Oct 22 & KY982323 \\
\hline A/TUR/219/2015.865* & Turkey & Düzce & Cattle & 2015 Nov 10 & KY982324 \\
\hline A/TUR/305/2015.923* & Turkey & Yozgat & Cattle & 2015 Nov 24 & KY982325 \\
\hline A/TUR/331/2015.923* & Turkey & Kütahya & Cattle & 2015 Nov 27 & KY982326 \\
\hline A/TUR/48/2016.019* & Turkey & Iğdir & Sheep & 2016 Jan 8 & KY982327 \\
\hline A/TUR/1008/2016.500* & Turkey & Muş & Cattle & 2016 Jun 29 & KY982328 \\
\hline A/TUR/1193/2016.731* & Turkey & Kastamonu & Cattle & 2016 Sep 21 & KY982329 \\
\hline A/TUR/1210/2016.750* & Turkey & Kars & Cattle & 2016 Sep 26 & KY982330 \\
\hline A/TUR/1218/2016.769* & Turkey & Tokat & Cattle & 2016 Oct 3 & KY982331 \\
\hline A/TUR/1225/2016.769* & Turkey & Gümüşhane & Cattle & 2016 Oct 6 & KY982332 \\
\hline A/TUR/1227/2016.750* & Turkey & Ardahan & Cattle & 2016 Sep 30 & KY982333 \\
\hline
\end{tabular}

*Non-World Reference Laboratory for Foot-and-Mouth Disease (Pirbright, UK) reference number. 


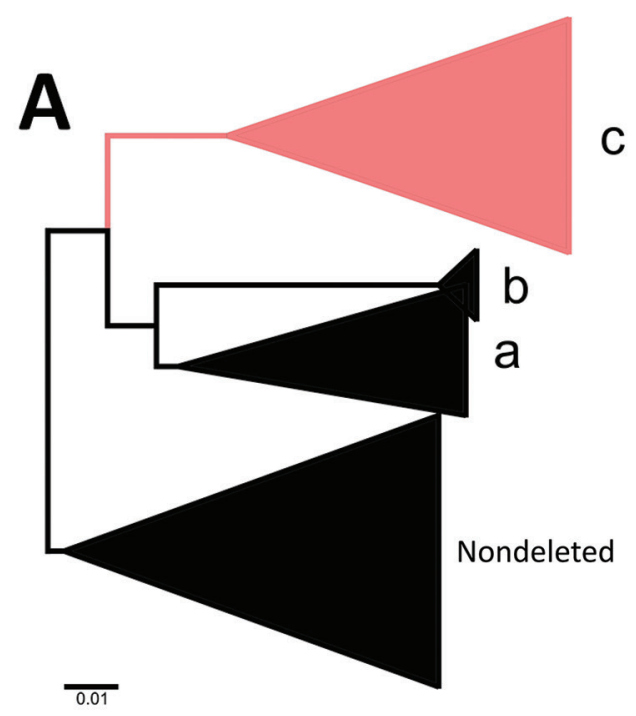

C

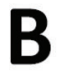

$\rightarrow$ AlRN/23/2016

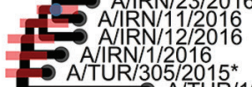
- ATUR/3050/2015 AlARM $1 / 2015^{\star}$ ANARMM ANTR/1227/2016* AARM/2/2015*

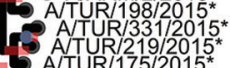
3 AllRN/13/2015 5 AIRN/27/2015/48/2016* - A/RN/25/2015
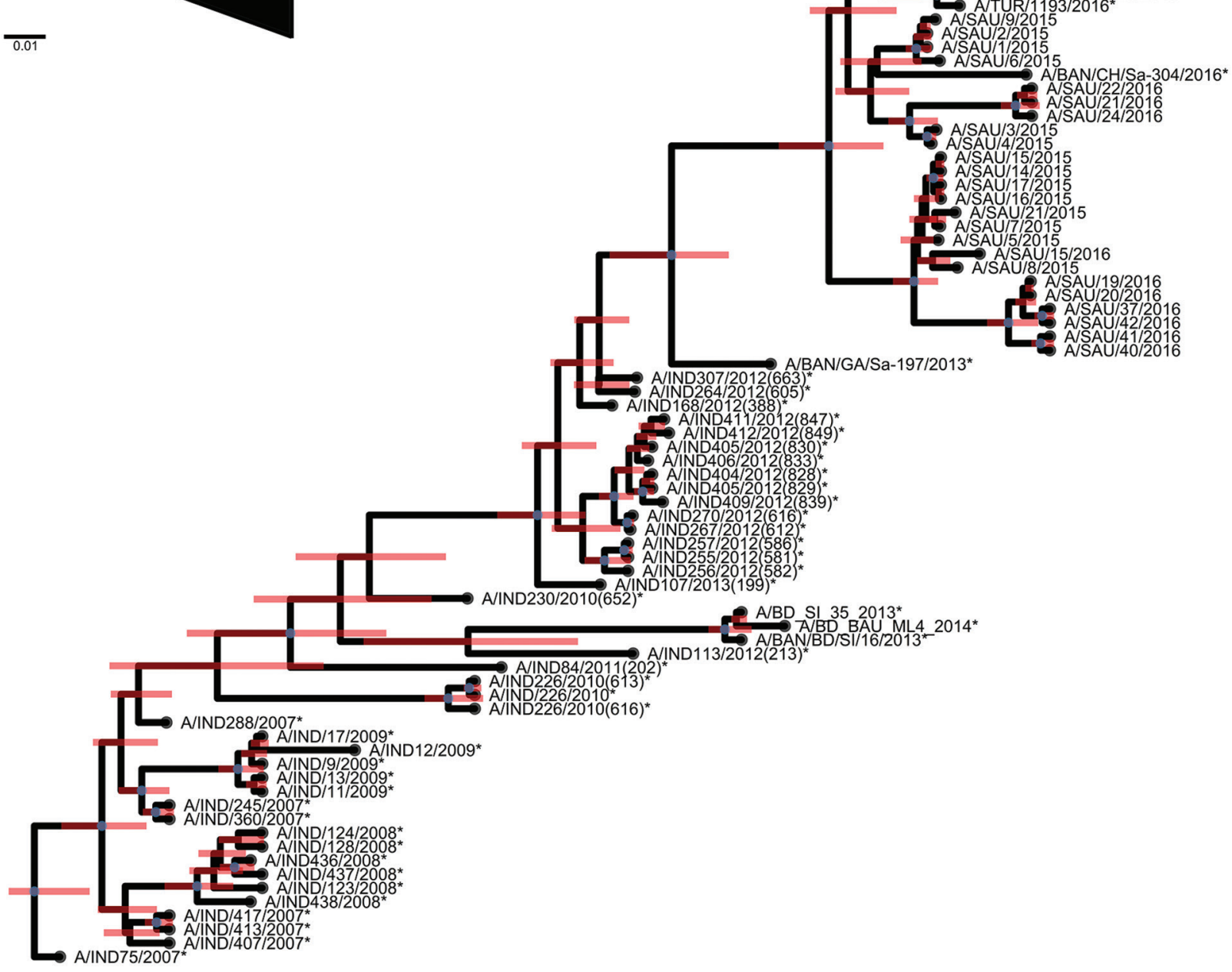

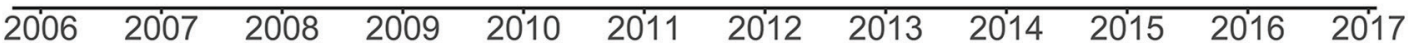

Figure 1. Phylogenetic analyses of viral protein 1-coding sequences of foot-and-mouth disease viruses classified within the A/ASIA/GVII lineage (isolated during 2006-2017) and reference viruses. A) Maximum-likelihood analysis showing 4 clades (sublineages). Scale bar indicates nucleotide substitutions per site. B) Bayesian phylogenetic analysis of viruses grouping within clade C. Red lines indicate $95 \%$ high posterior density of the most recent common ancestor. *Non-World Reference Laboratory for Foot-and-Mouth Disease (Pirbright, UK) reference number. ARM, Armenia; BAN, Bangladesh; IND, India; IRN, Iran; SAU, Saudi Arabia; TUR, Turkey. 
burn-in of 20 million steps. We assessed convergence and good mixing of the Markov Chain Monte Carlo C chain by using Tracer version 1.6 (http://beast.community/tracer).
VP1 coding region-based Bayesian analyses identified $\geq 2$ independent introductions of G-VII virus into the study region, $\geq 1$ to Saudi Arabia and 1 to Iran (Figure 1, panel B).

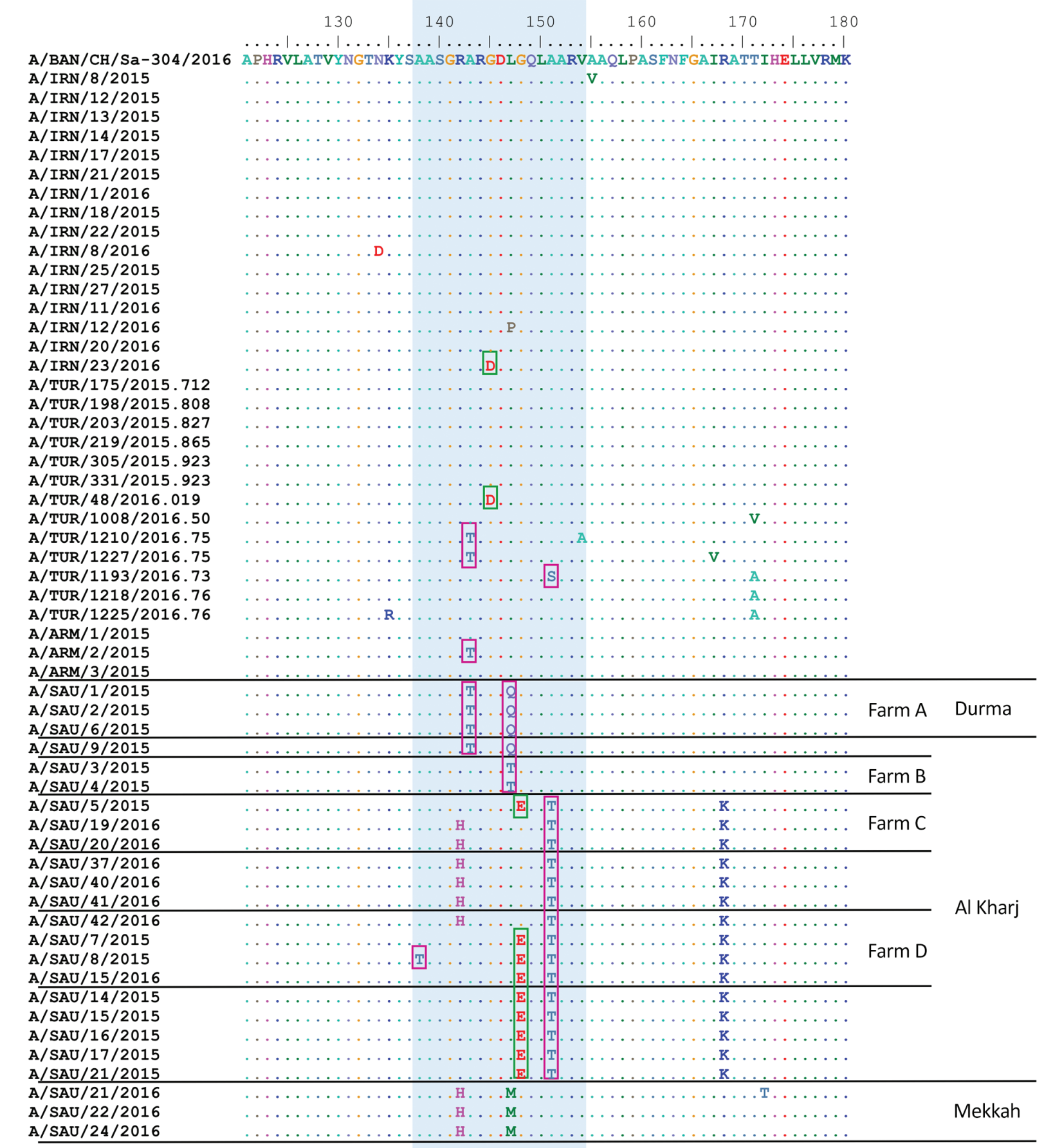

Figure 2. Comparison of predicted amino acid sequences of foot-and-mouth disease viruses showing changes in major antigenic sites. Predicted amino acid sequences for samples collected during outbreaks of foot-and-mouth disease during 2015-2016 were compared with A/BAN/CH/Sa-304/2016 virus sequence. Blue shading indicates conservative changes within antigenic site 1, pink boxes indicate hydrophobic to hydrophilic substitutions, and green boxes indicate hydrophobic to acidic substitutions. Dots indicate sequence identity. Amino acid residues are colored according to their physicochemical properties. Four large dairy farms (containing $>1,000$ lactating cows), which were multiply sampled, are indicated. ARM, Armenia; BAN, Bangladesh; IRN, Iran; SAU, Saudi Arabia; TUR, Turkey. 
However, lack of sequences for recent viruses circulating in the Indian subcontinent makes it difficult to resolve more precisely the number of introductions. Closely related viruses might be circulating in a wider geographic area, thus being a source of the outbreaks. However, this speculation is not supported by available epidemiologic information.

Outbreaks in Armenia, Iran, and Turkey were closely related and most likely originated from the same source. The most recent common ancestor (MRCA) was dated to March 2015 (95\% high posterior density [HPD] October 2014-July 2015). The MRCA of the C clade was dated to January 2006 (95\% HPD June 2005-April 2006), which is consistent with the first isolate obtained in India during 2007 (2). The MRCA of the phylogenetic cluster grouping Middle East (Saudi Arabia, Iran, and Turkey) isolates was dated to July 2015 (95\% HPD April-October 2015). Potential movement of G-VII FMDV lineages from the Indian subcontinent might be dated to October 2014 (95\% HPD January 2014-February 2015). Evolution of the GVII $\mathrm{C}$ clade lineage was estimated as having a mutation rate of $1.1 \times 10^{-2} \mathrm{nt} / \mathrm{site} / \mathrm{y}\left(95 \%\right.$ HPD $8.0 \times 10^{-3}$ to $1.4 \times$ $\left.10^{-2} \mathrm{nt} / \mathrm{site} / \mathrm{y}\right)$.

Amino acid substitutions on the FMDV surface, particularly in the G-H loop of VP1 (antigenic site 1), have been implicated in antigenic variation of the virus in vitro and in vivo (11). Predicted amino acid sequences obtained from samples collected during outbreaks in 2015-2016 were compared with the A/BAN/CH/Sa$304 / 2016$ sequence (most closely related virus from the Indian subcontinent), and 8 nonconservative substitutions were identified at 6 positions $(138,143,145,147$, 148 , and 151) within the VP1 antigenic site $1(12,13)$ (Figure 2; Table).

Changes from hydrophobic (alanine and leucine) to hydrophilic (threonine, glutamine, and serine) amino acid residues were most common, found at 4 positions; changes from hydrophobic (glycine) to acidic (aspartic acid and glutamic acid) amino acids were found at 2 positions. Antigenic variation at site 1 of type $\mathrm{C}$ viruses is often based on alternate switching between alanine and threonine residues without accumulation of amino acid substitutions (14). In addition, 2 independent changes that did not alter the amino acid characteristics were identified at positions 142 and 147 . We also showed that changes at antigenic site 1 were conserved mainly within but differed between farms, supporting independent selection pressures. Although the same vaccine was used, the intensive and frequent vaccination regimen routinely used on the affected farms in Saudi Arabia might have led to an independent antigenic evolution on an individual farm level from chance substitutions. Nevertheless, occasional substitutions within antigenic site 1 were also observed in Armenia, Turkey, and Iran (Figure 2).

\section{Conclusions}

As reported for the O/ME-SA/Ind-2001d virus lineage (15), A/ASIA/G-VII is the second FMDV lineage believed to have originated in the Indian subcontinent since 2013 and resulted in extensive outbreaks outside its usual area of distribution. Similar to the Ind-2001d outbreaks, current outbreaks caused by the G-VII lineage appear to be linked to multiple introductions of the virus from the Indian subcontinent; the virus then spread among susceptible ruminant populations in Saudi Arabia, Iran, Turkey, and Armenia.

It is a concern that in vitro vaccine matching data (by virus neutralization) provide poor confidence that commercially available vaccines would offer effective protection against the G-VII lineage (A. Ludi, pers. comm., May 2016). To improve control programs, it is crucial to identify expected routes of FMDV escape (e.g., international trade in animals and animal products) outside historically defined geographic distribution, and to establish transmission pathways within affected areas. To reconstruct likely transmission pathways at greater resolution, genome sequencing of viruses described in this report is currently in progress.

This study was supported by the Department for Environment, Food and Rural Affairs, United Kingdom (research grant SE2943). The World Reference Laboratory for Foot-and-Mouth Disease was supported by the European Union (contract from the European Commission for the Control of Foot-and-Mouth Disease, Rome, Italy). The Pirbright Institute was supported by a grant from the Biotechnology and Biological Sciences Research Council of the United Kingdom.

\section{About the Author}

Dr. Bachanek-Bankowska is a senior research scientist at the Food and Agriculture Organization of the United Nations World Reference Laboratory for FMD at The Pirbright Institute, United Kingdom. Her primary research interests are molecular epidemiology and development of molecular diagnostic methods for FMDV.

\section{References}

1. Knowles NJ, Samuel AR. Molecular epidemiology of foot-and-mouth disease virus. Virus Res. 2003;91:65-80. http://dx.doi.org/10.1016/S0168-1702(02)00260-5

2. Das B, Mohapatra JK, Pande V, Subramaniam S, Sanyal A. Evolution of foot-and-mouth disease virus serotype A capsid coding (P1) region on a timescale of three decades in an endemic context. Infect Genet Evol. 2016;41:36-46. http://dx.doi.org/10.1016/j.meegid.2016.03.024

3. Nandi SP, Rahman MZ, Momtaz S, Sultana M, Hossain MA. Emergence and distribution of foot-and-mouth disease virus serotype A and O in Bangladesh. Transbound Emerg Dis. 2015; 62:328-31. http://dx.doi.org/10.1111/tbed.12113

4. Jangra RK, Tosh C, Sanyal A, Hemadri D, Bandyopadhyay SK. Antigenic and genetic analyses of foot-and-mouth disease virus type $\mathrm{A}$ isolates for selection of candidate vaccine strain reveals emergence of a variant virus that is responsible for most recent 
outbreaks in India. Virus Res. 2005;112:52-9. http://dx.doi.org/ 10.1016/j.virusres.2005.03.021

5. Mohapatra JK, Subramaniam S, Pandey LK, Pawar SS, De A, Das B, et al. Phylogenetic structure of serotype A foot-and-mouth disease virus: global diversity and the Indian perspective. J Gen Virol. 2011;92:873-9. http://dx.doi.org/10.1099/vir.0.028555-0

6. Indian Council of Agricultural Research-Directorate on Foot and Mouth Disease. Annual report 2015-2016 [cited 2018 Feb 5]. http://www.pdfmd.ernet.in/index_files/Content/Reports/ PDFMD_AR 2015_16_English.pdf

7. Bachanek-Bankowska K, Wadsworth J, Thapa B, King DP, Knowles NJ. Complete genome sequence of a serotype A foot-andmouth disease virus from an outbreak in Saudi Arabia during 2015. Genome Announc. 2016;4:e01591-15.

8. Knowles NJ, Wadsworth J, Bachanek-Bankowska K, King DP. VP1 sequencing protocol for foot and mouth disease virus molecular epidemiology. Rev Sci Tech. 2016;35:741-55. http://dx.doi.org/10.20506/rst.35.3.2565

9. Drummond AJ, Suchard MA, Xie D, Rambaut A. Bayesian phylogenetics with BEAUti and the BEAST 1.7. Mol Biol Evol. 2012;29:1969-73. http://dx.doi.org/10.1093/molbev/mss075

10. Drummond AJ, Ho SY, Phillips MJ, Rambaut A. Relaxed phylogenetics and dating with confidence. PLoS Biol. 2006;4:e88. http://dx.doi.org/10.1371/journal.pbio.0040088
11. Grubman MJ, Baxt B. Foot-and-mouth disease. Clin Microbiol Rev. 2004;17:465-93. http://dx.doi.org/10.1128/ CMR.17.2.465-493.2004

12. Thomas AA, Woortmeijer RJ, Puijk W, Barteling SJ. Antigenic sites on foot-and-mouth disease virus type A10. J Virol. 1988;62:2782-9.

13. Bolwell C, Clarke BE, Parry NR, Ouldridge EJ, Brown F, Rowlands DJ. Epitope mapping of foot-and-mouth disease virus with neutralizing monoclonal antibodies. J Gen Virol. 1989;70:5968. http://dx.doi.org/10.1099/0022-1317-70-1-59

14. Martínez MA, Dopazo J, Hernández J, Mateu MG, Sobrino F, Domingo E, et al. Evolution of the capsid protein genes of foot-and-mouth disease virus: antigenic variation without accumulation of amino acid substitutions over six decades. J Virol. 1992;66:3557-65.

15. Knowles NJ, Bachanek-Bankowska K, Wadsworth J, Mioulet V, Valdazo-González B, Eldaghayes IM, et al. Outbreaks of foot-andmouth disease in Libya and Saudi Arabia during 2013 due to an exotic O/ME-SA/Ind-2001 lineage virus. Transbound Emerg Dis. 2016;63:e431-5. http://dx.doi.org/10.1111/tbed.12299

Address for correspondence: Katarzyna Bachanek-Bankowska, The Pirbright Institute, Ash Rd, Pirbright, Woking, Surrey, GU24 0NF, UK; email:kasia.bankowska@pirbright.ac.uk

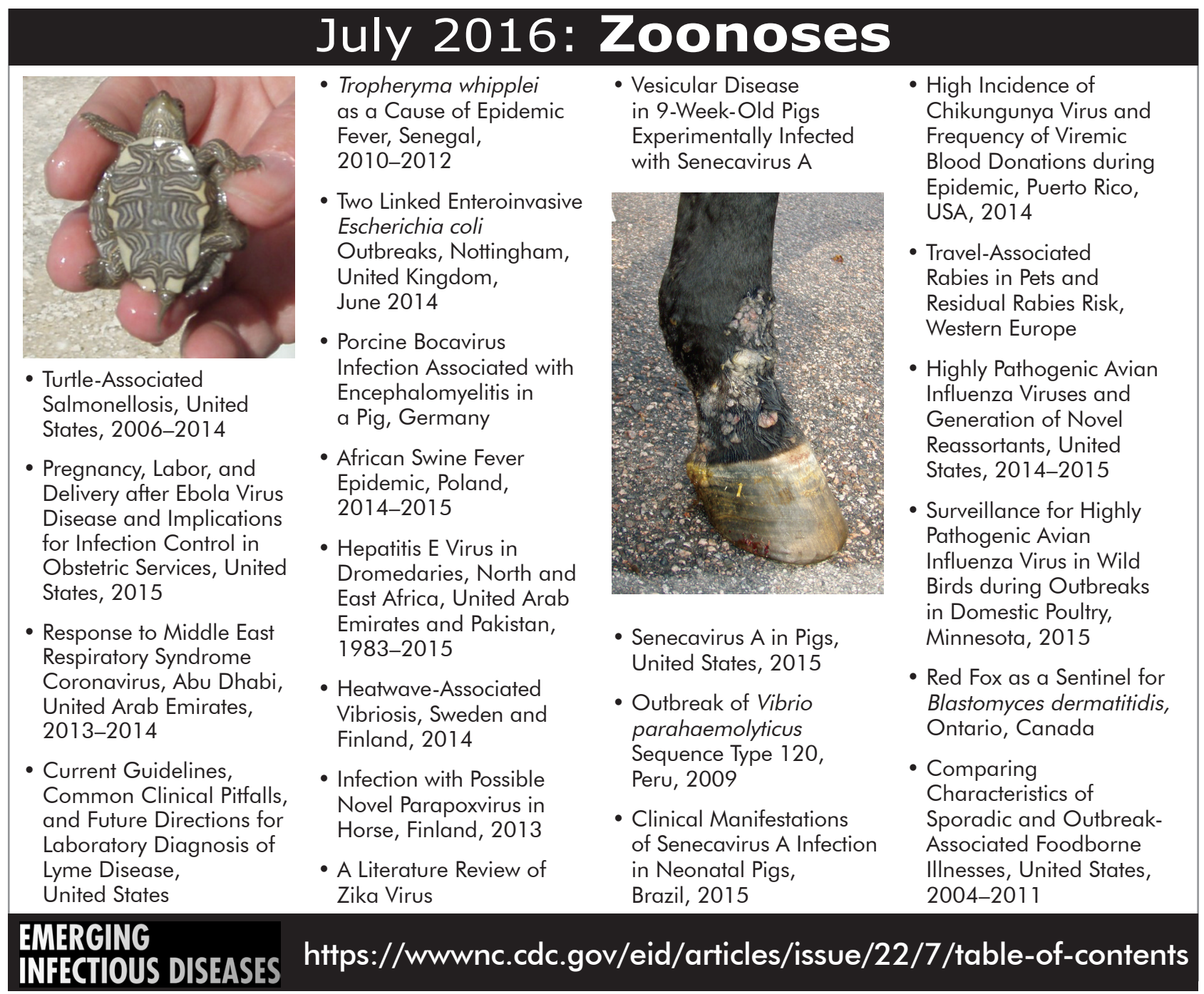

